\title{
Meiotic arrest as an alternative to increase the production of bovine embryos by somatic cell nuclear transfer
}

\author{
F.M.C. Caixeta ${ }^{2}$, R.V. Sousa ${ }^{3}$, A.L. Guimarães ${ }^{2}$, L.O. Leme², J.F.W. Sprícigo², S.B. Senna Netto ${ }^{2}$, \\ I. Pivato ${ }^{2}$ and M.A.N. Dode ${ }^{1,3}$ \\ School of Agriculture and Veterinary Medicine, University of Brasilia, Brasília-DF, Brazil; and EMBRAPA Genetic Resources \\ and Biotechnology, Brasília-DF, Brazil.
}

Date submitted: 29.02.2016. Date revised: 01.07.2016. Date accepted: 16.08.2016

\section{Summary}

This study aimed to evaluate the effect of meiotic arrest using phosphodiesterase type 3A (PDE 3A) inhibitors, cilostamide and C-type natriuretic peptide (NPPC), on pre-maturation (PM) of oocytes to be used in the production of cloned embryos. Nuclear maturation, in vitro embryo production (IVP), somatic cell nuclear transfer (SCNT) and parthenogenetic activation (PA), and total cells number of cloned embryos were evaluated. The results were analysed by chi-squared and Kruskal-Wallis test with a $P$-value $<0.05$ considered to be significant. Approximately $87.8 \%$ of the oocytes remained at germinal vesicle stage $(\mathrm{GV})$ after $6 \mathrm{~h}$ of PM with $5 \mu \mathrm{M}$ of cilostamide, confirming the meiotic block. Embryo development in IVP was similar $(P>0.05)$ between control and PM, both for cleavage $(78.2 \%$ and $76.9 \%)$ and blastocyst $(35.5 \%$ and $29.3 \%)$ rates. After SCNT, cleavage rate was also similar $(P>0.05)$ between control and PM (66\% and 51.9\%) however, blastocyst rate was lower $(P<0.05)$ in the PM group than in the control group (7.4\% and 30.2\%). After $6 \mathrm{~h}$ of PM with $100 \mathrm{nM}$ of NPPC, approximately $84.9 \%$ of the oocytes remained at GV. No difference was found between control and PM in cleavage $(69.2 \%$ and $76.1 \%)$ and blastocyst rates (37,4\% and 35\%) after IVP. Similarly, no differences between PM and control groups were observed for cleavage $(69.2 \%$ and $68.4 \%)$ and blastocyst $(24.4 \%$ and $21.5 \%)$ rates. SCNT and PA embryos from control or PM oocytes had similar total cell number. It can be concluded that PM for $6 \mathrm{~h}$ with $100 \mathrm{nM}$ NPPC is feasible for cloned embryo production without affecting embryo outcome.

Keywords: Cilostamide, NPPC, Oocyte, Pre-maturation, SCNT

\section{Introduction}

Despite the advances made in animal reproduction biotechnologies in the last few years, cloning by nuclear transfer using somatic cells (SCNT) is still inefficient.

\footnotetext{
${ }^{1}$ All correspondence to: Margot Alves Nunes Dode, EMBRAPA Genetic Resources and Biotechnology, Parque Estação Biológica, Final Av. W5/N, Prédio PBI, 70770-900, Brasília-DF, Brazil. Tel: +55 61 34484659. Fax: +55 613340 3658. E-mail: margot.dode@embrapa.br

${ }^{2}$ School of Agriculture and Veterinary Medicine, University of Brasilia, Brasília-DF, Brazil.

${ }^{3}$ EMBRAPA Genetic Resources and Biotechnology, BrasíliaDF, Brazil.
}

In cattle, although the blastocyst production is similar to that obtained in in vitro production of embryos (IVEP), (Iwamoto et al., 2015; Song et al., 2015; Jeong et al., 2013; Kato et al., 2000), a high rate of fetal loss is observed at the beginning of pregnancy (Keefer, 2015). These losses generally occur during placentation and have been related to epigenetic changes caused by failures in reprogramming of the differentiated donor cells (Campbell et al., 2007). Until the reprogramming problems of SCNT are solved, to increase the production of cloned products it is necessary to increase the number of embryos produced. To do that we have to face two main problems: the first refers to in vitro maturation (IVM), because when oocytes are removed from their follicles they spontaneously resume meiosis without undergoing so called 'oocyte 
capacitation', which is essential for the oocyte be fully competent for development (Luciano et al., 2011). The second challenge is the limited number of oocytes that a technician is able to micromanipulate efficiently in the cloning routine, associated with the short period of oocyte viability.

One alternative to try to improve the quality and provide a greater number of oocytes for micromanipulation would be to pre-mature the extra oocytes obtained in a routine day. Pre-matured oocytes can be kept arrested at the GV stage of the meiotic division before being subjected to IVM. In vitro pre-maturation (IVPM) has been suggested as a means to provide the oocyte with additional time in which to acquire developmental competence prior to IVM (Hendriksen et al., 2000; Hashimoto et al., 2002; Adona \& Leal, 2004). However, it can be very useful for routine SCNT by providing matured oocytes different times, allowing more flexibility in manipulations, and thus, enabling the use of the oocytes from a single batch of ovaries in 2 or more consecutive sets of micromanipulation. To block the spontaneous resumption of meiosis, various pharmacological substances have been used in the bovine oocyte, such as 6-dimethylaminopurine (6DMAP), which acts on the meiosis promoting factor (MPF) and specific inhibitors of cyclin-dependent kinases (CDKs), such as butyrolactone-I and roscovitine (Dode \& Adona, 2001; Adona \& Leal, 2004; Adona et al., 2008; Barretto et al., 2011; Marques et al., 2011). More recently, inhibitors of phosphodiesterase type 3 A (PDE-3A), which are specific to the oocytes (Sasseville et al., 2009), such as cilostamide and Ctype natriuretic peptide (NPPC), have been extensively used for the pre-maturation of bovine oocytes to be used in IVEP, in an attempt to increase the oocyte and embryonic development competence (Albuz et al., 2010; Dieci et al., 2013; Franciosi et al., 2014; De Cesaro et al., 2015; Farghaly et al., 2015; Guimaraes et al., 2015; Guimaraes et al., 2016).

Although the increases in production and quality of IVP embryos when pre-maturation is used is controversial (Gilchrist \& Thompson, 2007; Vanhoutte et al., 2008; Guimaraes et al., 2015, 2016), the lack of deleterious effects is a consensus among different authors (Jee et al., 2009; Franciosi et al., 2014; Guimaraes et al., 2016; Dieci et al., 2013). Therefore, this procedure would be of great value for routine cloning, because even if it does not cause an improvement in the quality of the oocyte, it allows large numbers of oocytes to be used in a single day without having aged oocytes, due to manipulation time. Nevertheless, there are only few reports of using PM in oocytes for SCNT, and there are no reports on using cilostamide and NPPC in cattle. Therefore, this study aimed to evaluate the use of PDE $3 \mathrm{~A}$ inhibitors for meiotic arrest of oocytes to be used for embryo production after SCNT.

\section{Materials and methods}

Unless otherwise stated, all reagents were purchased from Sigma-Aldrich Chemical Co. (St. Louis, MO, USA).

\section{Recovery and selection of oocytes}

Ovaries from crossbred cows (Bos taurus indicus $\times$ Bos taurus taurus) were collected at a local slaughterhouse and transported to the laboratory in $0.9 \%$ saline solution $(\mathrm{NaCl} 0.9 \%$ ), supplemented with streptomycin sulphate $100 \mu \mathrm{g} / \mathrm{ml}$ and penicillin $\mathrm{G}$ $(100 \mathrm{IU} / \mathrm{ml})$ at $35-36^{\circ} \mathrm{C}$. Cumulus-oocyte complexes (COCs) were aspirated from 3- to 8-mm diameter follicles with a syringe and an 18-gauge needle and pooled in a $15-\mathrm{ml}$ conical tube (TPP ${ }^{\circledR}$, Trasadingen, Schaffhausen, Switzerland). After sedimentation $10 \mathrm{ml}$ of the supernatant follicle fluid was centrifuged for 5 min at $700 \mathrm{~g}$, and used for search and selection of the COCs. Only COCs with four or more layers of cumulus cell (CC) and homogeneous cytoplasm were used on the experiment.

\section{Pre-maturation (PM) and maturation (IVM) of cumulus-oocyte complexes (COCs)}

Selected COCs were washed and transferred, in quantities of 30 to 35 , to a $200-\mu \mathrm{L}$ drop of either PM or maturation medium covered with silicone oil (Medical Fluid 360 DOW CORNING ${ }^{\circledR} 350$ CST-, New York, Canton, USA). PM medium consisted of TCM-199 (Gibco ${ }^{\circledR}$ ) Earle's salts supplemented with $0.075 \mathrm{mg} / \mathrm{ml}$ of amikacin, $0.2 \%$ bovine serum albumin, free fatty acids (FAF-BSA), $0.68 \mathrm{mM}$ L-glutamine, $1 \mu \mathrm{M}$ sodium pyruvate, $0.1 \mu \mathrm{M}$ cysteamine and $10^{-4} \mathrm{UI} / \mathrm{ml}$ recombinant FSH $\left[\mathrm{rFSH}\left(\right.\right.$ Gonal-F ${ }^{\circledR}$, Serono, Rockland, MA, USA] and to this was added $5 \mu \mathrm{M}$ of cilostamide or $100 \mathrm{nM}$ of NPPC. for a period of $6 \mathrm{~h}$, at $38.5^{\circ} \mathrm{C}$ and $5 \% \mathrm{CO}_{2}$ in air. The IVM medium consisted of TCM-199 Earl's salts $\left(\right.$ Gibco $\left.^{\circledR}\right)$ supplemented with $10 \%$ FBS fetal bovine serum $\left(\mathrm{Gibco}^{\circledR}\right), 12 \mathrm{IU} / \mathrm{ml}$ luteinizing hormone (LH), $0.01 \mathrm{IU} / \mathrm{ml}$ of follicle stimulating hormone (FSH) $0.1 \mathrm{mg} / \mathrm{ml}$ L-glutamine, $0.075 \mathrm{mg} / \mathrm{ml}$ amikacin, 0.1 $\mu \mathrm{M} / \mathrm{ml}$ cysteamine and $0.2 \mathrm{mM}$ sodium pyruvate. The IVM was performed for $20 \mathrm{~h}$ at $38.5^{\circ} \mathrm{C}$ and $5 \%$ $\mathrm{CO}_{2}$ in air. Those oocytes that were PM for $6 \mathrm{~h}$ were subsequently transferred to maturation in conditions similar to those of the control oocytes.

\section{Preparation of somatic cells for nuclear transfer}

Nuclear donor cell cultures were established from a skin biopsy of an adult Nellore male. Fibroblasts were in vitro cultured in Dulbecco's modified Eagle's medium (DMEM, GIBCO Life Technologies, Carlsbad, CA, USA) supplemented with $10 \%$ FCS and those from 
first through fourth passages were frozen with $10 \%$ of dimethyl sulfoxide (DMSO, GIBCO BRL). Before SCNT, the skin fibroblasts were thawed and cultured until reaching confluency. Cells were recovered after treatment with $0.25 \%$ trypsin and were transferred into the perivitelline space of an enucleated oocyte.

\section{Preparation and micromanipulation of oocytes}

After maturation, COCs was subjected to repeated pipetting for complete removal of the CC. Oocytes were then selected for the presence of polar body (PB), and homogeneity of the cytoplasm. Approximately 40 to 50 selected oocytes were transferred for $50 \mathrm{ml}$ drop of IVM medium solution containing cytochalasin D $(2.5 \mathrm{mg} / \mathrm{ml})$ and Hoechst $33342(1 \mathrm{mg} / \mathrm{ml})$, where they were kept for $30 \mathrm{~min}$ at $38.5^{\circ} \mathrm{C}$ in $5 \% \mathrm{CO}_{2}$ in air. Then a glass pipette (15-20 $\mu \mathrm{m}$ inner diameter) was used to enucleate the COCs by aspirating the first PB and a small amount of surrounding cytoplasm.

A somatic cell previously trypsinized was injected into the perivitelline space of an enucleated oocyte using the same glass pipette. The structures were transferred to D-mannitol solution $0.28 \mathrm{M}$ containing $0.1 \mathrm{mM}$ of $\mathrm{MgSO}_{4}$, and were subjected to electrofusion process on ECM $200\left(\mathrm{BTX}^{\circledR}\right)$ source. Electrofusion was performed in the fusion chamber by generating two electrical pulses of $2.1 \mathrm{kVA} / \mathrm{cm}$ and $30 \mu \mathrm{s}$ duration. Afterwards, the oocytes were returned to IVM medium where they were kept for $30 \mathrm{~min}$ for fusion evaluation.

Fused structures were activated by incubation for $5 \mathrm{~min}$ in LAV solution containing ionomycin $(5 \mu \mathrm{M})$ and then for $4 \mathrm{~h}$ in embryo culture medium synthetic oviduct fluid (SOFaaci), supplemented with essential and non-essential amino acids, $0.34 \mathrm{mM}$ sodium tricitrate, $2.77 \mathrm{mM}$ myo-inositol and 5\% FBS (Gibco) (SOFaaci; Holm et al., 1999) containing $2 \mu \mathrm{M}$ 6DMAP. Simultaneously with the micromanipulated oocytes, about 20-30 denuded oocytes, in the presence of $\mathrm{CP}$ and homogeneous cytoplasm, underwent the same activation procedures, and were considered parthenogenetically activated and used as a control group.

\section{In vitro fecundation (IVF)}

After the IVM, COCs were transferred to drops of $200 \mu \mathrm{l}$ of fertilization medium, consisting of Tyrode's through Albumin Lactate Pyruvate (TALP), supplemented with $0.5 \mathrm{mM} / \mathrm{ml}$ of penicillamine, $0.25 \mathrm{mM}$ hypotaurine, $25 \mathrm{mM}$ epinephrine and 10 $\mathrm{mg} / \mathrm{ml}$ of heparin. Frozen semen from the same bull, previously tested for in vitro production of embryos, was used for all treatments and replicates. After thawing, the sperm were selected by Percoll gradient method (GE ${ }^{\circledR}$ Healthcare, Piscataway, NJ, USA) using $90 \%(400 \mu \mathrm{l})$ and $45 \%(400 \mu \mathrm{l})$ in $1.5 \mathrm{ml}$ microcentrifuge tubes, and were centrifuged for $5 \mathrm{~min}$ at $9000 \mathrm{rpm}$ or $700 \mathrm{~g}$. The obtained pellet was resuspended and added dropwise into fertilization medium in order to obtain a final concentration of $1 \times 10^{6}$ mobile spermatozoa $/ \mathrm{ml}$. The oocytes were co-incubated with the sperm at $38.5^{\circ} \mathrm{C}$ and $5 \% \mathrm{CO}_{2}$ in air for a period of $18 \mathrm{~h}$. The day of insemination was regarded as day 0 (D0).

\section{In vitro culture of embryos}

Presumptive zygotes were cultured in $200 \mu$ l droplets of SOFaaci medium covered with mineral oil at $38.5^{\circ} \mathrm{C}$ in $5 \% \mathrm{CO}_{2}$ in air for seven days. Zygotes derived from SCNT and parthenogenesis were placed on a monolayer of CC established $24 \mathrm{~h}$ earlier. Initially, in all experiments embryos were assessed for cleavage at second day of culture (D2) and blastocyst formation at D7.

\section{Nuclear maturation kinetics}

To assess the stages of meiotic maturation, oocytes were removed from IVM culture, denuded, fixed for $48 \mathrm{~h}$ in ethanol and acetic acid (3:1) and stained with lacmoid $45 \%$ in glacial acetic acid. The evaluation of meiotic stages was performed in phase contrast microscopy (Nikon Eclipse E200, ×1000 magnification), and oocytes were classified as germinal vesicle $(\mathrm{GV})$, germinal vesicle broken down (GVBD), metaphase I (MI), anaphase I (AI), telophase I (IT) and metaphase II (MII).

\section{Total cell number}

At D7 embryos were incubated in a Hoechst 33342 solution $(1 \mathrm{mg} / \mathrm{ml})$ diluted in PBS (phosphatebuffered saline) without fetal bovine serum, at $38.5^{\circ} \mathrm{C}$ in $5 \% \mathrm{CO}_{2}$ for $20 \mathrm{~min}$. Then they were placed on slides and covered with cover slip. The number of total cells was determined by epifluorescence microscopy (Zeiss Axiophot, Germany R; filter 24 with a wavelength of 330-365 nm excitation / emission) $(\times 100)$.

\section{Statistical analysis}

The nuclear maturation and embryo development data were analysed by chi-squared test $(P<0.05)$ and total cell number using the Kruskal-Wallis test $(P<0.05)$.

\section{Results}

\section{Effect of $6 \mathrm{~h}$ of PM with cilostamide on nuclear maturation and on the developmental competence of bovine embryos produced by SCNT or IVF}

First, we assessed the ability of cilostamide to maintain oocyte meiotic arrest for $6 \mathrm{~h}$. At $0 \mathrm{~h}$, before being placed 
Table 1 Meiotic stages of bovine oocytes pre-matured (PM) or not (IVM) with $5 \mu \mathrm{M}$ of cilostamide at $0,6,14$ or 20 h of in vitro maturation (IVM)

\begin{tabular}{|c|c|c|c|c|c|}
\hline \multirow[b]{2}{*}{ Hours of culture treatments } & \multirow[b]{2}{*}{$N$} & \multicolumn{4}{|c|}{ Meiotic stages $(\%)$} \\
\hline & & GV & GVBD & MI, AI, TI & M II \\
\hline $0 \mathrm{~h}$ & 68 & $66(97.1)^{a}$ & $2(2.9)^{b, c}$ & $0(0.0)^{d}$ & $0(0)^{d}$ \\
\hline $6 \mathrm{~h} \mathrm{PM}$ & 65 & $57(87.8)^{b}$ & $6(9.2)^{b}$ & $2(3.1)^{d}$ & $0(0)^{d}$ \\
\hline $6 \mathrm{~h} \mathrm{IVM}$ & 52 & $37(71.2)^{c}$ & $14(26.9)^{a}$ & $1(1.9)^{d}$ & $0(0)^{d}$ \\
\hline $6 \mathrm{~h} \mathrm{PM}+14 \mathrm{~h}$ IVM & 52 & $1(1.9)^{d}$ & $0(0)^{c}$ & $36(69.2)^{b}$ & $15(28.8)$ \\
\hline $14 \mathrm{~h}$ IVM & 60 & $0(0)^{d}$ & $0(0)^{c}$ & $60(100)^{a}$ & $0(0)^{d}$ \\
\hline $6 \mathrm{~h} \mathrm{PM}+20 \mathrm{~h} \mathrm{IVM}$ & 40 & $0(0)^{d}$ & $0(0)^{c}$ & $1(2.5)^{d}$ & $39(97.5)$ \\
\hline $20 \mathrm{~h} \mathrm{IVM}$ & 55 & $0(0)^{d}$ & $0(0)^{c}$ & $8(14.5)^{c}$ & $47(85.5)^{l}$ \\
\hline
\end{tabular}

${ }^{a-d}$ Different letters in the same columns indicate significant differences by chi-squared test $(P<0.05)$. GV, germinal vesicle; GVBD, germinal vesicle breakdown; MI, metaphase 1; AI, anaphase 1; TI, Telophase 1; MII, metaphase II.

in culture, most oocytes from the control group were at the GV stage. In the groups exposed to the presence of cilostamide for $6 \mathrm{~h}$, although the percentage of oocytes at GV was lower than in the control at $0 \mathrm{~h}$, it also had the majority of the oocytes at GV (Table 1). At $20 \mathrm{~h}$ of maturation, it was observed that COCs submitted to retention for $6 \mathrm{~h}$ showed a higher percentage of oocytes that reached the MII stage (Table 1) than those from the control group. To assess the effect of PM for $6 \mathrm{~h}$ with $5 \mu \mathrm{M}$ of cilostamide on cytoplasmic maturation, treated and untreated oocytes were subjected to IVF. No differences $(P>0.05)$ between treatments was observed for cleavage and blastocyst rate (Table 2), showing no effect of treatment on the capacity of the oocyte to develop to the blastocyst stage.

When the effect of PM with cilostamide was evaluated on cloned embryo production, a similar $(P>0.05)$ cleavage rate was observed for oocytes undergoing PM within the two groups, SCNT and PA (Table 3). However, the PA group had a higher $(P<$ $0.05)$ cleavage rate than the SCNT group, regardless of whether the oocytes were submitted to PM or not. Although the D7 blastocyst rate was similar for the two groups of oocytes undergoing PA, a lower blastocyst rate $(P<0.05)$ was detected on the PM SCNT group than the IVM SCNT group (Table 3).

Table 2 Effect of pre-maturation (PM) for $6 \mathrm{~h}$ with $5 \mu \mathrm{M}$ cilostamide or not (IVM) in bovine oocytes in the cleavage and blastocyst rates after in vitro fertilization and culture

\begin{tabular}{lccc}
\hline & & \multicolumn{2}{c}{ No. embryos $(\%)$} \\
\cline { 3 - 4 } Treatment & $N$ & $\begin{array}{l}\text { Cleavage } \\
\text { rate at D2 }\end{array}$ & $\begin{array}{c}\text { Blastocyst } \\
\text { rate at D7 }(\%)\end{array}$ \\
\hline IVM & 133 & $104(78.2)$ & $47(35.5)$ \\
PM & 147 & $113(76.9)$ & $43(29.3)$ \\
\hline
\end{tabular}

Data analysed by chi-squared test $(P<0.05)$.

\section{Effect of $6 \mathrm{~h}$ of PM with natriuretic peptide type C (NPPC) on nuclear maturation and on the developmental competence of bovine embryos produced by SCNT or IVF}

Similarly to the cilostamide experiment, initially we evaluated the effect of NPPC to retain the progress of meiosis. The results indicated that after $6 \mathrm{~h}$ of PM, more than $80 \%$ of oocytes exposed to NPPC were at the GV stage (Table 4). At $20 \mathrm{~h}$ of maturation, the MII oocyte rate was similar $(P>0.05)$ for oocytes from $\mathrm{PM}$ and control group as shown in Table 4. When the oocytes undergoing PM with $100 \mathrm{nM}$ of NPPC were submitted to in vitro fertilization and culture, it was observed that the embryo development was similar ( $P$ $>0.05$ ) to the control oocytes (Table 5).

The results of using NPPC in PM of oocyte to produce cloned embryos are shown in Table 6. The cleavage rate was lower $(P<0.05)$ in the PM-PA group than in the other groups, which did not differ among themselves $(P>0.05)$. However, the use of oocytes submitted to PM with NPPC did not affect $(P>0.05)$ blastocyst rate of SCNT and PA embryos (Table 6).

Table 3 Effect of pre-maturation (PM) for $6 \mathrm{~h}$ with $5 \mu \mathrm{M}$ cilostamide or not (IVM) on cleavage and blastocyst rates of bovine oocytes submitted to somatic cell nuclear transfer (SCNT) or parthenogenetic activation (PA)

\begin{tabular}{lrrr}
\hline & & \multicolumn{2}{c}{ No. embryos $(\%)$} \\
\cline { 3 - 4 } Treatments & $N$ & $\begin{array}{c}\text { Cleavage } \\
\text { rate at D2 }\end{array}$ & $\begin{array}{c}\text { Blastocyst } \\
\text { rate at D7 }\end{array}$ \\
\hline IVM-PA & 115 & $103(89.6)^{a}$ & $55(47.8)^{a}$ \\
PM- PA & 94 & $81(86.2)^{a}$ & $47(50.0)^{a}$ \\
IVM- SCNT & 53 & $35(66.0)^{b}$ & $16(30.2)^{b}$ \\
PM- SCNT & 54 & $28(51.9)^{b}$ & $4(7.4)^{c}$ \\
\hline
\end{tabular}

${ }^{a-d}$ Different letters in the same columns indicate significant differences by chi-squared test $(P<0.05)$. 
Table 4 Meiotic stages of bovine oocytes pre-matured (PM) or not (IVM) with $100 \mathrm{nM}$ of natriuretic peptide type C (NPPC) at $0,6,14$ and $20 \mathrm{~h}$ of in vitro maturation (IVM)

\begin{tabular}{|c|c|c|c|c|c|}
\hline \multirow[b]{2}{*}{ Hours of culture treatment } & \multirow[b]{2}{*}{$N$} & \multicolumn{4}{|c|}{ Meiotic stages $(\%)$} \\
\hline & & GV & GVBD & MI, AI,TI. & MII \\
\hline $0 \mathrm{~h}$ & 59 & $59(100)^{a}$ & $0(0)^{c}$ & $0(0)^{e}$ & $0(0)^{c}$ \\
\hline $6 \mathrm{~h} \mathrm{PM}$ & 53 & $45(84.9)^{b}$ & $4(7.5)^{b}$ & $4(7.5)^{c, d}$ & $0(0)^{c}$ \\
\hline $6 \mathrm{~h} \mathrm{IVM}$ & 50 & $24(48)^{c}$ & $24(48)^{a}$ & $2(4.0)^{d, e}$ & $0(0)^{c}$ \\
\hline $6 \mathrm{~h} \mathrm{PM}+14 \mathrm{~h} \mathrm{IVM}$ & 52 & $0(0)^{d}$ & $0(0)^{c}$ & $40(76.9)^{b}$ & $12(23.1)^{b}$ \\
\hline $14 \mathrm{~h} \mathrm{IVM}$ & 61 & $0(0)^{d}$ & $0(0)^{c}$ & $58(95.1)^{a}$ & $3(4.9)^{c}$ \\
\hline $6 \mathrm{~h} \mathrm{PM}+20 \mathrm{~h} \mathrm{IVM}$ & 51 & $0(0)^{d}$ & $0(0)^{c}$ & $8(15.7)^{c}$ & $43(84.3)^{a}$ \\
\hline 20 h IVM & 55 & $0(0)^{d}$ & $0(0)^{c}$ & $9(15.8)^{c}$ & $48(84.2)^{a}$ \\
\hline
\end{tabular}

${ }^{a-d}$ Different letters in the same columns indicate significant differences by chi-square test $(P<0.05)$. GV, germinal vesicle; GVBD, germinal vesicle breakdown; MI, metaphase 1; AI, anaphase 1; TI, Telophase 1; MII, metaphase II.

Table 5 Effect of pre-maturation (PM) for $6 \mathrm{~h}$ with $100 \mathrm{nM}$ of natriuretic peptide type C (NPPC) or not (IVM) in bovine oocytes in the cleavage and blastocyst rate after fertilization and in vitro culture

\begin{tabular}{lccc}
\hline & & \multicolumn{2}{c}{ No. embryos $(\%)$} \\
\cline { 3 - 4 } Treatments & $N$ & $\begin{array}{l}\text { Cleavage } \\
\text { rate at D2 }\end{array}$ & $\begin{array}{l}\text { Blastocyst } \\
\text { rate at D7 }\end{array}$ \\
\hline IVM & 115 & $80(69,6)$ & $43(37,4)$ \\
PM & 117 & $89(76,1)$ & $41(35)$ \\
\hline
\end{tabular}

Data analysed by chi-squared test $(P<0.05)$.

To investigate the quality of cloned embryos, total cell number was evaluated, which was similar for all treatments (Table 7).

\section{Discussion}

SCNT is well known for generating numerous problems such as placental abnormalities, respiratory problems, oversized organs, obesity, short lifespan,

Table 6 Effect of pre-maturation (PM) for $6 \mathrm{~h}$ with $100 \mathrm{nM}$ of natriuretic peptide type C (NPPC) or not (IVM) on cleavage and blastocyst rate of bovine oocytes submitted to somatic cell nuclear transfer (SCNT) or parthenogenetic activation (PA)

\begin{tabular}{lrrr}
\hline & & \multicolumn{2}{c}{ No. embryos $(\%)$} \\
\cline { 3 - 4 } Treatments & $N$ & $\begin{array}{l}\text { Cleavage } \\
\text { rate at D2 }\end{array}$ & $\begin{array}{l}\text { Blastocyst } \\
\text { rate at D7 }\end{array}$ \\
\hline IVM-PA & 102 & $82(80.4)^{a}$ & $47(46.1)^{a}$ \\
PM-PA & 95 & $62(65.3)^{b}$ & $40(42.1)^{a}$ \\
IVM- SCNT & 79 & $54(68.4)^{a}$ & $17(21.5)^{b}$ \\
PM- SCNT & 78 & $54(69.2)^{a}$ & $19(24.4)^{b}$ \\
\hline
\end{tabular}

${ }^{a-d}$ Different letters in the same columns indicate significant differences by chi-squared test $(P<0.05)$. fetal edema, prolonged gestation, dystocia, hydramnios, and perinatal death. Most of those problems have been associated with delayed or incompleted reprogramming of the differentiated nucleus to an embryonic state (Smith et al., 2000; Santos et al., 2003; Latham, 2005; Niemann et al., 2008; Smith et al., 2012; Hosseini et al., 2016). Therefore, while the mechanism of reprogramming or the mechanism that leads to deregulation of genes involved in extra-embryonic tissue modelling is still not clear, the only way to increase the number of cloned products is by increasing the number of oocytes used for a routine NT.

The oocyte plays a key role in the outcome of SCNT, since its cytoplasm should contain all the reprogramming factors that can erase the epigenetic pattern of the donor cell nucleus. Furthermore, the oocyte is responsible for embryonic development until maternal-zygotic transition has occurred (Sirard, 2001). Therefore, it is expected that the better the quality of the oocyte the higher are its chances of success in SCNT.

Another factor related to oocyte quality that has to be considered in SCNT tecnique is the time required for the micromanipulation and the short period in

Table 7 Total cell number of somatic cell nuclear transfer (SCNT) or parthenogenetically activated cloned embryos produced from the pre-matured oocytes (PM) with $100 \mathrm{nM}$ of natriuretic peptide type C (NPPC) for $6 \mathrm{~h}$ or not (IVM) at $\mathrm{d} 7$

\begin{tabular}{lcc}
\hline Treatments & $\begin{array}{c}\text { Number of } \\
\text { embryos }\end{array}$ & $\begin{array}{c}\text { Total cell number } \\
(\text { mean } \pm \text { SD) }\end{array}$ \\
\hline IVM-PA & 18 & $116.33 \pm 28.7$ \\
PM-PA & 20 & $114.15 \pm 27.5$ \\
IVM- SCNT & 8 & $131.25 \pm 47.8$ \\
PM- SCNT & 12 & $118.91 \pm 54.03$ \\
\hline
\end{tabular}

Data analysed by Kruskal-Wallis test $(P<0.05)$. PA, parthenogenic activation. 
which the oocyte remains viable without suffering the adverse effects of ageing. Therefore, the number of oocytes that can be micromanipulated is limited by those factors, which ultimately affects the number of embryos produced.

Assuming that the time of micromanipulation is crucial to the success of the SCNT technique, and that oocytes need to be synchronized with the nucleus to be transferred, we propose an alternative procedure that may allow technicians to micromanipulate a greater number of oocytes on one day of manipulation, without affecting their quality. Various substances that increase levels of cAMP have been shown to be efficient in inhibiting spontaneous meiosis resumption in cattle (Dode \& Adona, 2001; Luciano et al., 2011; Franciosi et al., 2014; Farghaly et al., 2015; Ulloa et al., 2015; Guimaraes et al., 2016). Recently, inhibitors of phosphodiesterase type 3 (PDE-3), which are specific to the oocytes (Sasseville et al., 2009; Albuz et al., 2010), and responsible for hydrolysing the cAMP, have been used (Vanhoutte et al., 2008; Chen et al., 2009; Jee et al., 2009; Luciano et al., 2011; Dieci et al., 2013; Lodde et al., 2013; Franciosi et al., 2014) in IVP. For the present study we chose to use two of those substances, cilostamide and NPPC, to block the spontaneous meiotic resumption.

In the first experiment, we evaluated the PM of COCs for $6 \mathrm{~h}$ using $5 \mu \mathrm{M}$ of cilostamide. Although a statistical difference in the percentage of oocytes at GV stage was detected between the groups $0 \mathrm{~h}$ and $6 \mathrm{~h}$ of PM, most oocytes submitted to PM were at GV stage. Therefore, it can be assumed that meiotic block had occurred, which can also be confirmed by the difference found between $6 \mathrm{~h}$ PM and $6 \mathrm{~h}$ IVM, where the latter showed the lowest percentage of oocytes at GV stage. These results are consistent with those found by other authors in several species (Luciano et al., 2011; Dieci et al., 2013; Buell et al., 2015; Farghaly et al., 2015), including bovine (Mayes \& Sirard, 2002; Albuz et al., 2010; Luciano et al., 2011; Ulloa et al., 2015). The effect of cilostamide in retaining meiosis is due to the inhibition of phosphodiesterase type 3A (PDE3A), which is responsible for cAMP hydrolysis and is specific to the oocyte (Sasseville et al., 2009). The oocyte arrest caused by PM was reversible because at $20 \mathrm{~h}$ of IVM post blockage, the percentage of oocytes at MII was similar to the control. However, an acceleration of maturational kinetics after meiotic arrest was observed since at $14 \mathrm{~h}$ of IVM after PM, around $30 \%$ of the oocytes had already reached MII stage, while none of the control group had completed meiosis. Similar results were reported by other authors (Adona \& Leal, 2004; Barretto et al., 2011; Guimaraes et al., 2016), however, the physiology and the implications have not been fully elucidated.
To ensure that the PM with cilostamide would not affect the cytoplasmic maturation and embryo development, the oocytes were submitted to IVP. The results showed that cleavage and blastocyst rates were similar to those of the control group. Although some studies reported the beneficial effect of meiotic retention with cilostamide in the bovine embryo production (Gilchrist \& Thompson, 2007; Vanhoutte et al., 2008), our results showed that PM for $6 \mathrm{~h}$ was not able to increase the developmental competence. However, no deleterious effect was observed, indicating that this procedure can be used to maintain longer viability of bovine oocytes. Similar results were found using PM in mouse oocytes (Jee et al., 2009). According to Luciano et al. (2011), the meiotic retention with cilostamide only increased the production of embryos when it was used in oocytes that had not yet reached their full growth (Luciano et al., 2011). Therefore, it is possible that the different results obtained can be due to the types of oocytes used, of wich some were growing and others fully grown. To evaluate the effect of PM with cilostamide on embryonic development after SCNT, oocytes that were parthenogenetically activated were used as controls. The cleavage rate and blastocyst after parthenogenic activation were similar between oocytes submitted or not to PM. However, a drastic reduction in the blastocyst rate was observed after SCNT when PM oocytes were used, compared to PM but parthenogenic. These results differ from those reported by De Bem et al. (2011), in which embryonic development after SCNT in cattle was similar between oocytes and control oocytes undergoing PM for $24 \mathrm{~h}$ with butyrolactone I (De Bem et al., 2011). Likewise, the use of PM for $24 \mathrm{~h}$ with cilostamide in pig oocytes did not affect blastocyst production after SCNT (Dieci et al., 2013).

The contrasting results are difficult to explain, considering that there are only a few studies using this type of procedure. The reason for the reduction in embryo production in our study is unclear, but it is possible that an interaction between the deleterious effect of micromanipulation and a possible negative effect of cilostamide might have happened. This hypothesis was based on studies in our laboratory with cilostamide, which showed that the concentration and exposure time of oocytes to cilostamide affects the subsequent embryo development. Therefore, considering that a high concentration of cilostamide can have some deleterious effects, we chose to use half of the dose, which we consider not to be harmful to oocytes (Guimaraes et al., 2016). However, it seems that when the oocytes were exposed to micromanipulation, the negative effect of cilostamide may have been exacerbated, resulting in a lower embryo production. This is the first study using PM with cilostamide in bovine oocytes for SCNT. 
Next, we tried to carry out a similar experiment, exchanging cilostamide for NPPC, which has been reported as having beneficial effects for bovine oocytes (Franciosi et al., 2014). Similarly to what was observed for cilostamide, the majority of the oocytes remained at GV stage after $6 \mathrm{~h}$ of PM. Acceleration of post meiotic arrest was also observed, but no difference in the percentage of oocytes at MII at $20 \mathrm{~h}$ of maturation. These results are consistent with those found in the literature (Franciosi et al., 2014; Zhong et al., 2015). NPPC is a natural agent, produced and released by the mural granulosa cells, and it binds with its NPR2 and NPR1 receptors which are associated with guanylate cyclase. This binding stimulates the production and release of cGMP, which enters the oocyte through Gap Junctions (GJs) inhibiting PDE3A activity and meiotic resumption (Zhang et al., 2010; Franciosi et al., 2014; Hiradate et al., 2014; Zhong et al., 2015).

Afterwards, we assessed if NPPC would affect the embryonic development. COCs exposed to NPPC for $6 \mathrm{~h}$ during PM underwent fertilization and culture for 7 days. The results obtained corroborate those reported by Franciosi et al in 2014, who showed that there was no difference in cleavage and blastocyst rates, ensuring no deleterious effect of PM with NPPC on COCs (Franciosi et al., 2014).

When oocytes undergoing PM with NPPC were used for SCNT, cleavage and blastocyst rates were similar to the control group. In other words, the PM with NPPC did not affect the outcome of SCNT embryos. Although there are no studies using NPPC to produce cloned embryos, the result corroborates others in which different inhibitors of meiosis resumption were used (De Bem et al., 2011; Dieci et al., 2013). Regarding the results of the previous experiment, it is possible that lowering the concentration of cilostamide could eliminate the deleterious effect observed when PM is associated with SCNT micromanipulation. However, it would be necessary to test if a lower concentration of cilostamide would be sufficient to inhibit the resumption of meiosis in cattle oocyte. This issue was not observed when using NPPC for meiotic arrest, possibly because it is a substance naturally present, and therefore, does not have a negative effect (Franciosi et al., 2014) even when associated with the stress of micromanipulation. Therefore, NPPC was shown to be a viable alternative for PM of oocytes to be used for SCNT embryo production.

Finally, to evaluate the quality of embryos produced after PM, the total cell number was used. No effect of PM or SCNT was observed. Our results showed no negative effect on the quality of embryos produced by SCNT from COCs pre-matured with NPPC, which is consistent with studies that produced cloned embryos with other inhibitors (De Bem et al., 2011) and IVP Embryos produced with NPPC (Franciosi et al., 2014). Although there is a difference found on literature results using total cell number (De Bem et al., 2011), which may be explained by the effect of micromanipulation. Total cell number did not differ between groups in this experiment.

The purpose of meiotic arrest is to enable the micromanipulation of a greater number of oocytes on the same day. In cloned embryo production, the retention period can be manipulated according to the laboratory routine, programming micromanipulation better, to achieve maximum production and efficiency.

According to the results, it can be concluded that the use of PM with cilostamide is able to promote meiotic arrest, but has a detrimental effect on the production of cloned embryos. In contrast, NPPC can be used in PM of bovine oocytes to be used in SCNT, enabling the use of a greater number of oocytes per micromanipulation per day and consequently increase the embryo production.

\section{Conflict of interest}

The authors declare that there is no conflict of interest that could be perceived as prejudicing the impartiality of the research reported.

\section{Acknowledgements}

This research was supported by EMBRAPA Microprograma 1 (grant number 003.0709040000) and FAP-DF, and was conducted at EMBRAPA Genetic Resources and Biotechnology and the University of Brasília in Brazil. The authors thank the personnel at QualiMax Meat Packing (Luziânia, Goiás, Brazil) and Nipobras slaughterhouse (Formosa, Goiás, Brazil) for their generosity in supplying ovaries for research.

\section{References}

Adona, P.R. \& Leal, C.L.V. (2004). Meiotic inhibition with different cyclin-dependent kinase inhibitors in bovine oocytes and its effects on maturation and embryo development. Zygote 12, 197-204.

Adona, P.R., Pires, P.R., Quetglas, M.D., Schwarz, K.R. \& Leal, C.L. (2008). Prematuration of bovine oocytes with butyrolactone I: effects on meiosis progression, cytoskeleton, organelle distribution and embryo development. Anim. Reprod. Sci. 108, 49-65.

Albuz, F.K., Sasseville, M., Lane, M., Armstrong, D.T., Thompson, J.G. \& Gilchrist, R.B. (2010). Simulated physiological oocyte maturation (SPOM): a novel in vitro maturation system that substantially improves embryo yield and pregnancy outcomes. Hum. Reprod. 25, 29993011.

Barretto, L.S.S., Caiado Castro, V.S.D., Garcia, J.M. \& Mingoti, G.Z. (2011). Meiotic inhibition of bovine oocytes in 
medium supplemented with a serum replacer and hormones: effects on meiosis progression and developmental capacity. Zygote 19, 107-16.

Buell, M., Chitwood, J.L. \& Ross, P.J. (2015). cAMP modulation during sheep in vitro oocyte maturation delays progression of meiosis without affecting oocyte parthenogenetic developmental competence. Anim. Reprod. Sci. 154, 16-24.

Campbell, K.H., Fisher, P., Chen, W.C., Choi, I., Kelly, R.D., Lee, J.H. \& Xhu, J. (2007). Somatic cell nuclear transfer: Past, present and future perspectives. Theriogenology 68(Suppl. 1), S214-31.

Chen, J., Chi, M.M., Moley, K.H. \& Downs, S.M. (2009). cAMP pulsing of denuded mouse oocytes increases meiotic resumption via activation of AMP-activated protein kinase. Reproduction 138, 759-70.

De Bem, T.H., Chiaratti, M.R., Rochetti, R., Bressan, F.F., Sangalli, J.R., Miranda, M.S., Pires, P.R., Schwartz, K.R., Sampaio, R.V., Fantinato-Neto, P., Pimentel, J.R., Perecin, F., Smith, L.C., Meirelles, F.V., Adona, P.R. \& Leal, C.L. (2011). Viable calves produced by somatic cell nuclear transfer using meiotic-blocked oocytes. Cell Reprogram. 13, 419-29.

De Cesaro, M.P., Macedo, M.P., Santos, J.T., Rosa, P.R., Ludke, C.A., Rissi, V.B., Gasperin, B.G. \& Goncalves, P.B. (2015). Natriuretic peptides stimulate oocyte meiotic resumption in bovine. Anim. Reprod. Sci. 159, 52-9.

Dieci, C., Lodde, V., Franciosi, F., Lagutina, I., Tessaro, I., Modina, S.C., Albertini, D.F., Lazzari, G., Galli, C. \& Luciano, A.M. (2013). The effect of cilostamide on gap junction communication dynamics, chromatin remodeling, and competence acquisition in pig oocytes following parthenogenetic activation and nuclear transfer. Biol. Reprod. 89, 68.

Dode, M.A.N. \& Adona, P.R. (2001). Developmental capacity of Bos indicus oocytes after inhibition of meiotic resumption by 6-dimethylaminopurine. Anim. Reprod. Sci. 65, 171-80.

Farghaly, T., Khalifa, E., Mostafa, S., Hussein, M., Bedaiwy, M. and Ahmady, A. (2015). The effect of temporary meiotic attenuation on the in vitro maturation outcome of bovine oocytes. In Vitro Cell. Dev. Biol. Anim. 51, 662-71.

Franciosi, F., Coticchio, G., Lodde, V., Tessaro, I., Modina, S.C., Fadini, R., Dal Canto, M., Renzini, M.M., Albertini, D.F. \& Luciano, A.M. (2014). Natriuretic peptide precursor $C$ delays meiotic resumption and sustains gap junctionmediated communication in bovine cumulus-enclosed oocytes. Biol. Reprod. 91, 61.

Gilchrist, R.B. \& Thompson, J.G. (2007). Oocyte maturation: emerging concepts and technologies to improve development potential in vitro. Theriogenology 67, 6-15.

Guimaraes, A.L., Pereira, S.A., Kussano, N.R. \& Dode, M.A. (2015). Evaluation of the simulated physiological oocyte maturation system for improving bovine in vitro embryo production. Theriogenology 83, 52-7.

Guimaraes, A.L., Pereira, S.A., Kussano, N.R. \& Dode, M.A. (2016). The effect of pre-maturation culture using phosphodiesterase type 3 inhibitor and insulin, transferrin and selenium on nuclear and cytoplasmic maturation of bovine oocytes. Zygote 24, 219-29.
Hashimoto, S., Minami, N., Takakura, R. \& Imai, H. (2002). Bovine immature oocytes acquire developmental competence during meiotic arrest in vitro. Biol. Reprod. 66, 1696-701.

Hendriksen, P.J.M., Vos, P.L.A.M., Steenweg, W.N.M., Bevers, M.M. \& Dieleman, S.J. (2000). Bovine follicular development and its effect on the in vitro competence of oocytes. Theriogenology 53, 11-20.

Hiradate, Y., Hoshino, Y., Tanemura, K. \& Sato, E. (2014). C-type natriuretic peptide inhibits porcine oocyte meiotic resumption. Zygote 22, 372-7.

Holm, P., Booth, P.J., Schmidt, M.H., Greve, T. \& Callesen, H. (1999). High bovine blastocyst development in a static in vitro production system using sofaa medium supplemented with sodium citrate and myo-inositol with or without serum-proteins. Theriogenology 52, 683700 .

Hosseini, S.M., Dufort, I., Nieminen, J., Moulavi, F., Ghanaei, H.R., Hajian, M., Jafarpour, F., Forouzanfar, M., Gourbai, H., Shahverdi, A.H., Nasr-Esfahani, M.H. \& Sirard, M.A. (2016). Epigenetic modification with trichostatin A does not correct specific errors of somatic cell nuclear transfer at the transcriptomic level; highlighting the non-random nature of oocyte-mediated reprogramming errors. BMC Genomics 17, 16.

Iwamoto, D., Yamagata, K., Kishi, M., Hayashi-Takanaka, Y., Kimura, H., Wakayama, T. \& Saeki, K. (2015). Early development of cloned bovine embryos produced from oocytes enucleated by fluorescence metaphase II imaging using a conventional halogen-lamp microscope. Cell Reprogram. 17, 106-14.

Jee, B.C., Chen, H.Y. \& Chian, R.C. (2009). Effect of a phosphodiesterase type 3 inhibitor in oocyte maturation medium on subsequent mouse embryo development. Fertil. Steril. 91, 2037-42.

Jeong, Y.I., Park, C.H., Kim, H.S., Jeong, Y.W., Lee, J.Y., Park, S.W., Lee, S.Y., Hyun, S.H., Kim, Y.W., Shin, T. \& Hwang, W.S. (2013). Effects of trichostatin A on in vitro development of porcine embryos derived from somatic cell nuclear transfer. Asian-Australas J. Anim. Sci. 26, 1680-8.

Kato, Y., Tani, T. \& Tsunoda, Y. (2000). Cloning of calves from various somatic cell types of male and female adult, newborn and fetal cows. J. Reprod. Fertil. 120, 231237.

Keefer, C.L. (2015). Artificial cloning of domestic animals. Proc. Natl. Acad. Sci. USA 112, 8874-8.

Latham, K.E. (2005). Early and delayed aspects of nuclear reprogramming during cloning. Biol. Cell 97, 119-32.

Lodde, V., Franciosi, F., Tessaro, I., Modina, S.C. \& Luciano, A.M. (2013). Role of gap junction-mediated communications in regulating large-scale chromatin configuration remodeling and embryonic developmental competence acquisition in fully grown bovine oocyte. J. Assist. Reprod. Genet. 30, 1219-26.

Luciano, A.M., Franciosi, F., Modina, S.C. \& Lodde, V. (2011). Gap junction-mediated communications regulate chromatin remodeling during bovine oocyte growth and differentiation through cAMP-dependent mechanism(s). Biol. Reprod. 85, 1252-9. 
Marques, M.G., Nascimento, A.B., Gerger, R.P., Goncalves, J.S., Coutinho, A.R., Simoes, R., Assumpcao, M.E. \& Visintin, J.A. (2011). Effect of culture media on porcine embryos produced by in vitro fertilization or parthenogenetic activation after oocyte maturation with cycloheximide. Zygote 19, 331-7.

Mayes, M.A. \& Sirard, M.-A. (2002). Effect of type 3 and type 4 phosphodiesterase inhibitors on the maintenance of bovine oocytes in meiotic arrest. Biol. Reprod. 66, 180-184.

Niemann, H., Tian, X.C., King, W.A. \& Lee, R.S. (2008). Epigenetic reprogramming in embryonic and foetal development upon somatic cell nuclear transfer cloning. Reproduction 135, 151-63.

Santos, F., Zakhartchenko, V., Stojkovic, M., Peters, A., Jenuwein, T., Wolf, E., Reik, W. \& Dean, W. (2003). Epigenetic marking correlates with developmental potential in cloned bovine preimplantation embryos. Curr. Biol. 13, 1116-21.

Sasseville, M., Albuz, F.K., Cote, N., Guillemette, C., Gilchrist, R.B. \& Richard, F.J. (2009). Characterization of novel phosphodiesterases in the bovine ovarian follicle. Biol. Reprod. 81, 415-25.

Sirard, M.A. (2001). Resumption of meiosis: mechanism involved in meiotic progression and its relation with developmental competence. Theriogenology 55, 1241-54.

Smith, L.C.B.V., Babkine, M., Fecteau, G. \& Keefer, C. (2000). Benefits and problems with cloning animals. Can. Vet. J. 41, 6 .
Smith, L.C., Suzuki Jr., J., Goff, A.K., Filion, F., Therrien, J., Murphy, B.D., Kohan-Ghadr, H.R., Lefebvre, R., Brisville, A.C., Buczinski, S., Fecteau, G., Perecin, F. \& Meirelles, F.V. (2012). Developmental and epigenetic anomalies in cloned cattle. Reprod. Domest. Anim. 47(Suppl. 4), 107-14.

Song, Z., Cong, P., Ji, Q., Chen, L., Nie, Y., Zhao, H., He, Z. \& Chen, Y. (2015). Establishment, differentiation, electroporation and nuclear transfer of porcine mesenchymal stem cells. Reprod. Domest. Anim. 50, 840-8.

Ulloa, S.M., Heinzmann, J., Herrmann, D., Timmermann, B., Baulain, U., Grossfeld, R., Diederich, M., LucasHahn, A. \& Niemann, H. (2015). Effects of different oocyte retrieval and in vitro maturation systems on bovine embryo development and quality. Zygote 23, 36777.

Vanhoutte, L., Nogueira, D., Gerris, J., Dhont, M. \& De Sutter, P. (2008). Effect of temporary nuclear arrest by phosphodiesterase 3-inhibitor on morphological and functional aspects of in vitro matured mouse oocytes. Mol. Reprod. Dev. 75, 1021-30.

Zhang, M., Su, Y.-Q., Sugiura, K., Xia, G. \& Eppig, J.J. (2010). Granulosa cell ligand NPPC and its receptor NPR2 maintain meiotic arrest in mouse oocytes. Science 330, 366-9.

Zhong, Y., Lin, J., Liu, X., Hou, J., Zhang, Y. \& Zhao, X. (2015). C-Type natriuretic peptide maintains domestic cat oocytes in meiotic arrest. Reprod. Fertil. Dev. doi: 10.1071/RD14425. [Epub ahead of print] 